\title{
Analisis Pelaksanaan Sistem Pencatatan dan Pelaporan Terpadu Puskesmas (SP2TP) di Kota Padang Tahun 2018
}

\author{
Laura $\mathrm{S}^{1}$, Firdawati $^{2}$, Edison $^{2}$
}

\begin{abstract}
Abstrak
Sistem Pencatatan dan Pelaporan Terpadu Puskesmas (SP2TP) merupakan kegiatan pencatatan dan pelaporan puskesmas secara menyeluruh (terpadu) dengan konsep wilayah kerja puskesmas. Permasalahan SP2TP di Kota Padang adalah sekitar $40 \%$ puskesmas yang menyerahkan laporan SP2TP tidak tepat waktu dan sekitar $70 \%$ dari seluruh laporan yang dikirim puskesmas ke Dinas Kesehatan masih kurang lengkap dan diragukan keakuratannya. Hal ini mengakibatkan keterlambatan Dinas Kesehatan Kota dalam menyerahkan laporan ke Dinas Kesehatan Provinsi dan ke Kementrian Kesehatan, hal lain juga berdampak pada penyusunan perencanaan program kesehatan yang tidak tepat sasaran. Tujuan: melihat pelaksanaan Sistem Pencatatan dan Pelaporan Terpadu Puskesmas (SP2TP) di Kota Padang Tahun 2018. Metode: studi kebijakan jenis kualitatif dengan wawancara mendalam, Focus Group Discussion dan telah dokumen, dengan jumlah 24 informan dari Dinas kesehatan dan Puskesmas Kota Padang. Hasil: Pelaksanaan SP2TP di Kota Padang belum optimal, yang disebabkan masih kurangnya tenaga terlatih SP2TP, sarana prasarana serta dana juga masih kurang. Simpulan: Proses pelaksanaan SP2TP masih belum mengikuti juknis yang ditetapkan oleh Kementerian Kesehatan, serta belum adanya pengorganisasian yang baik, dan sistem pencatatan dan pelaporan yang masih manual.
\end{abstract}

Kata kunci: SP2TP, kualitatif, puskesmas

\begin{abstract}
Integrated Recording and Reporting System for Health Center (SP2TP) is a comprehensive (integrated) recording and reporting of Health Center with the concept of Health Center working area. The problem of SP2TP in Padang City is that about four percent of the Health Center that submit SP2TP reports are not on time and about seventy percent of all reports sent by Health Center to the Health Office are still incomplete and doubtful about their accuracy. This resulted in delays in the City Health Office in submitting reports to the Provincial Health Office and to the Ministry of Health, other things also had an impact on the planning of health programs that were not on target. Objectives: To saw the implementation of the Integrated Health Center Recording and Reporting System (SP2TP) in Padang City in 2018. Methods:This research was a qualitative policy study design with in-depth interviews, focus group discussions and documents, on twenty-four informants from the Health Office and the Padang City Health Center. Results: The implementation of SP2TP in the city of Padang is not optimal, due to the lack of trained SP2TP staff, lack of facilities and funds. Conclusions: SP2TP implementation process still not following the technical guidelines set by the Ministry of Health, and lack of good organization, and recording and reporting systems that are still manual
\end{abstract}

Keywords: SP2TP, qualitative, health center

Affiliasi penulis: 1. Dinas Kesehatan Kota Padang, 2. Bagian IImu Kesehatan Masyarakat Fakultas Kedokteran Universitas Andalas Padang

Korespondensi: laura.suciono@gmail.com

\section{PENDAHULUAN}

Tantangan pembangunan kesehatan menuntut adanya dukungan sumber daya yang cukup serta arah kebijakan dan strategi pembangunan kesehatan yang tepat.Kesulitan pengambil kebijakan dalam pengambil 
keputusan yang tepat karena keterbatasan atau ketidaktersedian data dan informasi yang akurat, tepat dan cepat. Hasil evaluasi Pusat Data dan Informasi tahun 2007 terhadap Sistem Informasi Kesehatan diketahui bahwa data yang ada tidak adekuat, dengan komponen penilaian sumber daya (47\%), indikator $(61 \%)$, sumber data $(51 \%)$, kualitas data $(55 \%)$, penggunaan dan diseminasi data (57\%) serta tidak adekuat sama sekali untuk managemen data (35\%). Hasil ini senada dengan evaluasi yang dilakukan oleh Departemen Kesehatan Republik Indonesia dalam Rencana Strategis Kementrian Kesehatan Republik Indonesia tahun 2010-2014 yang menemukan permasalahan pada sistem informasi kesehatan di Indonesia. Keberadaan data diera desentralisasi menjadi lemah, kebutuhan data dan informasi untuk evidance planning tidak tersedia tepat waktu, meskipun Sistem Informasi Kesehatan Nasional (SIKNAS) online sudah terintegrasi. ${ }^{1}$

Salah satu Sistem Informasi Kesehatan Puskesmas (SIMPUS) di Indonesia adalah Sistem Pencatatan dan Pelaporan Terpadu Puskesmas (SP2TP) yang merupakan serangkaian kegiatan pencatatan dan pelaporan data umum, sarana, tenaga dan upaya pelayanan kesehatan di Puskesmas yang mengacu kepada Peraturan Pemerintah Republik Indonesia Nomor 46 Tahun 2014. Sistem Pencatatan dan Pelaporan Terpadu Puskesmas (SP2TP) merupakan kegiatan pencatatan dan pelaporan puskesmas secara menyeluruh (terpadu) dengan konsep wilayah kerja puskesmas. Sistem pelaporan ini diharapkan mampumemberikan informasi baik bagi puskesmas maupun untuk jenjang administrasi yang lebih tinggi, guna mendukung manajemen kesehatan. ${ }^{2}$

Puskesmas merupakan fasilitas pelayanan kesehatan primer yang menyelenggarakan upaya kesehatan masyarakat dan upaya kesehatan perseorangan tingkat pertama, untuk mencapai derajat kesehatan masyarakat yang setinggi-tingginya di wilayah kerjanya. Pengoptimalan fungsi puskesmas tersebut memerlukan manajemen puskesmas yang didukung sistem pencatatan dan pelaporan yang berkualitas, untuk keperluan tersebut dibutuhkan dukungan sistem informasi puskesmas yang baik, mulai dari pengumpulan data hasil pelaksanaan kegiatan, sampai pada pengolahan dan pemanfaatannya. ${ }^{3}$ Hal ini dipertegas dalam Permenkes Nomor 75 Tahun 2014 tentang pusat kesehatan masyarakat, bahwa sistem informasi puskesmas diperlukan untuk membantu proses pengambilan keputusan dalam melaksanakan manajemen puskesmas untuk mencapai sasaran kegiatan. Melalui SP2TP, Puskesmas diwajibkan mengumpulkan data transaksi pelayanan baik pelayanan Unit Kesehatan Perorangan (UKP) dan Unit Kesehatan Masyarakat (UKM) secara rutin. Melalui semua program yang ada di Puskesmas, diwajibkan membuat laporan bulanan ke dinas kesehatan melalui format Laporan Bulanan (LB) yang berisi data pasien selama sebulan, namun dalam pelaksanaanya pembuatan laporan tersebut ditemukan banyak kendala seperti kesalahan pencatatan, pencatatan ganda sehingga berakibat kepada ketidakpastian hasil dari laporan tersebut. ${ }^{4}$

Kota Padang adalah ibu kota provinsi Sumatera Barat, dimana kegiatan program yang dilakukan akan menjadi acuan dari kota/ kabupaten lainnya. Begitu pula dengan kegiatan program SP2TP. Kota Padang memiliki 23 Puskesmas yang melakukan pencatatan dan laporan untuk menghasilkan suatu informasi kesehatan terkait seluruh pelaksanaan program di tingkat puskesmas, dan dilaporkan secara rutin ke Dinas Kesehatan Kota setiap bulannya. Pada tingkat Dinas Kesehatan (Dinkes), laporan tersebut akan diolah kembali dan mengirimkan umpan baliknya ke Dinas Kesehatan Provinsi dan ke Kementrian Kesehatan. Feed Back terhadap laporan puskesmas akan dikirimkan kembali secara rutin ke puskesmas untuk dapat dijadikan evaluasi keberhasilan program. ${ }^{2}$. Berdasarkan survey pendahuluan melalui wawancara dan observasi yang dilakukan, permasalahan lain yang ditemukan di Dinas Kesehatan Kota Padang diantaranya: banyaknya jumlah formulir dan data yang harus diisi oleh petugas, kekurangan tenaga yang kompeten, khususnya tenaga rekam medis. Untuk tenaga rekam medis yang ada di Kota Padang hanya 17 orang dari 23 puskesmas yang ada. Petugas pengelola SIK atau SP2TP harus menguasai ilmu statistik. ${ }^{5}$

Penelitian pendahuluan terhadap laporan evaluasi program SP2TP di Dinas Kesehatan Kota padang, diketahui bahwa permasalahan keterlamatan penyerahan laporan SP2TP di Dinas Kesehatan Kota Padang, selalu saja terjadi setiap bulannya sampai saat ini, dari 23 puskesmas yang ada di Kota Padang, rata- rata hanya $40 \%$ puskesmas yang menyerahkan laporan SP2TP tepat waktu. Permasalahan lainnya adalah masih adanya 
sekitar $60 \%$ dari seluruh laporan yang dikirim puskesmas ke Dinas Kesehatan masih kurang lengkap dan diragukan keakuratannya. Hal ini mengakibatkan keterlambatan Dinkes Kota dalam menyerahkan laporan ke Dinas Kesehatan Provinsi dan ke Kementrian Kesehatan, hal lain juga berdampak pada penyusunan perencanaan program kesehatan yang tidak tepat sasaran.

Berdasarkan uraian di atas, perlu membuat analisis bagaimanapelaksanaan Sistem Pencatatan dan Pelaporan Terpadu Puskesmas (SP2TP) di Kota Padang Tahun 2018.

\section{METODE}

Rancangan dalam penelitian ini menggunakan jenis penelitian kualitatif, yang bertujuan untuk mendapatkan gambaran secara mendalam tentang bagaimanapelaksanaan Sistem Pencatatan dan Pelaporan Terpadu Puskesmas (SP2TP) di Kota Padang tahun 2018. Informan dalam penelitian ini adalah Kepala Dinas Kesehatan Kota Padang, Penanggungjawab SIK Dinas Kesehatan Kota Padang, Kepala Puskesmas, Penanggungjawab SP2TP Puskesmas. Alat yang digunakan dalam penelitian ini adalah pedoman wawancara mendalam (Indepth interview), Pedoman Focus Group Discussion (FGD) serta daftar telaah dokumen dengan observasi mendalam serta menggunakan bantuan alat perekam elektronik (tape recorder), kamera dan buku catatan. Sumber data terdiri dari data primer dan sekunder ${ }^{6}$

Sumber data primer terdiri dari hasil observasi langsung pelaksanaan Sistem Pencatatan dan Pelaporan Terpadu Puskesmas (SP2TP) di Kota Padang Tahun 2018, hasil wawancara mendalam dengan informan dan hasil Focus Group Discussion. Data sekunder didapat dari sumber tertulis berupa dokumen terkait pelaksanaan Sistem Pencatatan dan Pelaporan Terpadu Puskesmas (SP2TP) di Kota Padang Tahun 2018

Analisis data dalam penelitian ini menggunakan model Miles and Huberman yaitu: (1) Reduksi Data, Mereduksi data berarti merangkum, memilih dan menentukan hal-hal yang pokok dan penting, kemudian menentukkan tema permasalahan. Reduksi data didapatkan melalui metode pengumpulan data yang telah dilakukan sehingga data yang direduksi dapat memberikan gambaran yang jelas tentang pengelolaan data dan informasi kesehatan. (2) Penyajian Data, Penyajian data akan disajikan dalam bentuk teks yang bersifat naratif, sehingga dapat lebih midah memahami apa yang sebenarnya terjadi Dalam proses pengelolaan data dan informasi kesehatan. (3) Penarikan Simpulan, Pengambilan kesimpulan dilakukan berdasarkan hasil reduksi data dan penyajian data dengan tetap mengacu pada rumusan masalah dan tujuan penelitian. ${ }^{6}$

HASIL

\section{Komponen Input}

a. Kebijakan

Hasil penelitian di Dinas Kesehatan dan 11 puskesmas yang ada di Kota Padang menunjukkan bahwa kebijakan yang dipakai pihak Puskesmas adalah kebijakan nasional Peraturan Menteri Kesehatan RI Nomor 75 Tahun 2014, artinya kebijakan ada disesuaikan dengan kebijakan kementerian kesehatan, sedangkan kebijakan khusus yang dikeluarkan oleh Dinas Kesehatan terkait SP2TP ini belum ada. ${ }^{4}$

\section{b. Pedoman PelaksanaanSistem Pencatatan dan \\ Pelaporan Terpadu Puskesmas (SP2TP)}

Pedoman yang dipakai untuk pelaksanaan Sistem Pencatatan dan Pelaporan Terpadu Puskesmas (SP2TP) di Kota Padang masih pedoman pelaksanaan Sistem Pencatatan dan Pelaporan Terpadu Puskesmas (SP2TP) dikeluarkan Kementerian Kesehatan. Buku pedoman ini hanya dimiliki oleh Dinas Kesehatan, dan tidak didistrinbusikan dan disosialisasikan ke Puskesmaspuskesmas. Untuk saat ini, tidak ada disusun Juknis pelaksanaan Sistem Pencatatan dan Pelaporan Terpadu Puskesmas (SP2TP) oleh Pemerintah Kota Padang. ${ }^{7}$

\section{c. Sumber Daya Manusia}

Berdasarkan hasil penelitian diketahui bahwa pemegang program SP2TP dipuskesmas berlatar belakang pendidikan perawat dan bidan, latar belakang pendidikan sangat mempengaruhi seseorang dalam melakukan pekerjaan. Dari latar belakang pendidikan koordinator SP2TP di Puskesmas Kota Padang sudah memenuhi kualifikasi dari pendidikan formal karena 
dirasa sudah memiliki kompetensi di bidang statistik dan komputer sesuai dengan Peraturan Pemerintah Nomor

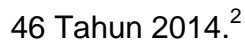

\section{d. Sarana dan Prasarana}

Hasil penelitian ketersediaan sarana komputer dalam pelaksanaan SP2TP dari sebelas Puskesmas yang diteliti, hanya tujuh Puskesmas yang memiliki komputer khusus SP2TP sedangkan 4 Puskesmas yaitu Puskesmas N, Puskesmas AA, Puskesmas SB dan Puskesmas $\mathrm{B}$, belum mempunyai komputer khusus untuk pelaksanaan SP2TP sehingga harus memanfaatkan komputer yang ada di Puskesmas bersama dengan program lainnya

\section{Komponen Proses}

a. Perencanaan Pelaksanaan sistem pelaporan SP2TP dari Puskesmas ke Dinas Kesehatan

Berdasarkan hasil penelitian yang dilakukan Di Dinas Kesehatan Kota Padang belum pernah dilakukan perencanaan terkait bagaimana sistem pelaporan SP2TP dari Puskesmas ke Dinas Kesehatan, perencanaan adanya evaluasi dan monitoring pun juga belum pernah dilakukan di Dinas Kesehatan, Hal yang sama juga terjadi di Puskesmas, perencanaan terkait pelaksanaan Program SP2TP belum pernah sama sekali dilakukan, karena pimpinan merasa belum perlunya perencanaan khusus, menurut mereka kegiatan SP2TP bisa berjalan seperti biasa tanpa harus adanya perencanaan khusus.

\section{b. Pengorganisasian}

Penelitian ini mendapatkan pengorganisasian SP2TP di Dinas Kesehatan belum ada, semua laporan SP2TP dari puskesmas langsung diserahkan ke masingmasing seksi program yang ada di Dinas Kesehatan, karena dalam beberapa tahun terakhir Dinas Kesehatan Kota Padang tidak mempunyai koordinator penanggung jawab pelaksana SP2TP, hal ini menjadi salah satu penghambat bagi kelancaran pelaksanaan SP2TP. Pada tingkat puskesmas, penggorganisasian SP2TP di Kota Padang sudah cukup baik, melalui kebijakan pimpinan puskesmas maka disetiap puskesmas sudah ditentukan penanggung jawab, koordinator dan anggota dari pelaksana SP2TP di puskesmas, namun penugasan ini belum disertai dengan adanya uraian tugas dan tanggungjawab yang harus dilakuka oleh petugas yang telah ditunjuk sebagai koordinator dan penanggung jawab.

\section{c. Pencatatan dan Pelaporan}

Wawancara dengan seluruh informan yang ada tahap pencatatan SP2TP di 11 Puskesmas Kota Padang, pada umumnya pencatatan yang dilakukan belum sesuai dengan pedoman SP2TP karena pencatatan yang dilakukan masih banyak data yang ada di formulir kosong untuk direkap, hal ini karena ada kegiatan yang tidak dilakukan puskesmas dan juga hal ini terjadi kekosongan data karena tidak terdapat penderita dan juga karena belum sampai laporan data yang diterima puskesmas dari pustu sehingga rekapitulasi terhadap pencatatan sering terjadi kekosongan data. Padahal seharusnya dilakukan secara rutin dan tercatat setiap bulannya. Pencatatan dalam SP2TP meliputi pencatatan kegiatan pokok puskesmas yang dilakukan didalam dan diluar gedung puskesmas, rawat inap, dan pustu.

Berdasarkan hasil penelitian yang telah dilakukan di Puskesmas Kota Padang, pelaporan SP2TP yang dilaksanakan oleh puskesmas adalah setelah pelaksana kegiatan melakukan pencatatan terhadap semua kegiatan yang ada di dalam dan diluar gedung puskesmas kemudian data tersebut direkapitulasi dan kemudian dikumpulkan ke koordinator yang sekaligus petugas SP2TP untuk kemudian di input kedalam formulir SP2TP oleh koordinator SP2TP yang juga sekaligus sebagai petugas SP2TP.

\section{d. Pengawasan dan Pengendalian}

Pelaksanaan SP2TP di Puskesmas Kota Padang selama ini masih belum dianggap hal yang penting, pimpinan dan petugas di Dinas Kesehatan dan Puskesmas beranggapan SP2TP hanya merupakan suatu kegiatan rutinitas yang dijalankan setiap tahunnya tanpa perlu dilakukan upaya peningkatan dalam menghasilkan kualitas data.

\section{Komponen Output}

Berdasarkan hasil penelitian ketepatan waktu puskesmas menyampaikan laporan dari 11 Puskesmas 
yang diteliti ada 4 Puskesmas yang memberikan laporan tidak tepat waktu yaitu: Puskesmas N, Puskesmas AA, Puskesmas SP dan Puskesmas B. Menurut peneliti, permasalahan tersebut tidak terlepas dari koordinasi antar petugas pelaksana kegiatan di dalam gedung maupun di luar gedung puskesmas dengan koordinator SP2TP serta penanggung jawab puskesmas itu sendiri, tidak tersedianya sarana dan prasarana yang menjadi penunjang seperti komputer khusus SP2TP dan jaringan wifi yang memadai, tidak adanya petugas khusus yang melakukan analisis dan penginputan data hal inilah yang menyebabkan laporan tidak tepat waktu disampaikan ke Dinas Kesehatan Kota, dan sangat berpengaruh pada kualitas laporan SP2TP, semua permasalahan diatas menjadi bagian dari faktor-faktor yang menghambat pelaksanaan SP2TP Di Wilayah Kerja Dinas Kesehatan Kota Padang. Penelitian yang dilakukan Vidyanto (2018), ketidaktepatan waktu pengiriman laporan dari Puskesmas Ke Dinas Kesehatan dipengaruhi oleh beberapa faktor diantaranya faktor geografis daerah, jumlah tenaga yang minim tetapi beban kerja tinggi, belum adanya media komunikasi elektronik serta pengiriman laporan masih dilakukan secara sederhana. ${ }^{8}$

\section{PEMBAHASAN}

\section{Komponen Input}

a. Kebijakan

Kebijakan yang dipakai pihak Puskesmas adalah kebijakan nasional Peraturan Menteri Kesehatan Nomor 75 Tahun 2014, namun untuk kebijakan pelaksanaan SP2TP ini belum diperkuat dengan SK ataupun peraturan walikota. ${ }^{4}$

Di tingkat provinsi/ kabupaten/ kota, pelaksanaan SIK juga harus didukung oleh suatu kebijakan yang memperkuatnya sebagai pijakan pelaksanaan bagi pengelola SIK di daerah. Setiap daerah (provinsi dan kabupaten/kota) membuat suatu surat keputusan daerah mengenai SIK yang ditandatangani oleh kepala daerah. Kepala institusi pelayanan kesehatan juga bisa mengeluarkan keputusan terkait SIK sesuai wilayah kerjanya, untuk memastikan pelaksanaan operasional. ${ }^{9}$ Tidak adanya kebijakan sangat mempengaruhi terhadap proses pengumpulan laporan SP2TP dari puskesmas ke Dinas Kesehatan, tidak adanya kebijakan khusus yang mengatur pengorganisasian SP2TP juga berdampak kepada tidak satu pintunya proses penerimaan laporan di Dinas Kesehatan sehingga laporan yang diterima langsung oleh masing-masing seksi yang ada di Dinas kesehatan.

\section{b. Pedoman pelaksanaan Sistem Pencatatan dan}

Pelaporan Terpadu Puskesmas (SP2TP)

Pedoman pelaksanaan Sistem Pencatatan dan Pelaporan Terpadu Puskesmas (SP2TP) yang tidak terdistribusi, maka dikeluarkan Kementerian Kesehatan serta tidak disusunnya Juknis pelaksanaan Sistem Pencatatan dan Pelaporan Terpadu Puskesmas (SP2TP) oleh Pemerintah Kota Padang menjadi salah satu faktor penghambat proses pelaksanaan SP2TP karena puskesmas tidak punya acuan dan pedoman tentang bagaimana seharusnya SP2TP dilaksanakan.

\section{c. Sumber Daya Manusia}

Pedoman yag dikeluarkan oleh Kementerian Kesehatan RI tahun 2011 semua tenaga SIK harus memiliki kompetensi, kompetensi merupakan kemampuan dan keahlian yang harus dimiliki petugas SP2TP, dalam pelaksanaan SP2TP petugas harus memahami bidang kesehatan baik aspek klinis maupun program kesehatan, petugas SIP juga harus mampu melakukan kegiatan statistik bidang kesehatan, memiliki kemampuan dalam bidang teknologi dalam bidang informasi. Berdasarkan penelitian yang dilakukan untuk kompetensi memahami bidang kesehatan diketahui jika petugas hanya memahami istilah-istilah kesehatan tetapi belum memahami indikator-indikator program. Kegiatan statistik bidang kesehatan oleh petugas hanya mampu mengumpulkan data, namun untuk validasi dan pengukuran indikator kesehatan belum dapat dilakukan oleh petugas. Kemampuan dalam bidang teknologi informasi semua petugas puskesmas sudah dapat menggunakan perangkat keras. ${ }^{7}$

Permasalahan lain SDM dalam penelitian ini juga berasal dari beban kerja yang mereka terima, seorang koordinator SP2TP harus mengerjakan tugas rangkap sebagai pengelola program SP2TP juga sebagai pemegang program puskesmas lainnya. Hal ini berdampak kepada tidak maksimalnya koordinator SP2TP melakukan pekerjaannya sebagai pengelola program SP2TP karena harus mengerjakan program 
puskesmas yang juga mempunyai target yang harus mereka capai, sehingga kegiatan SP2TP sering terabaikan.

Berdasarkan semua kendala terkait SDM SP2TP di Puskesmas mestinya Kepala Puskesmas dalam perencanaan terkait pemberian tugas ditahun yang akan datang, tidak lagi memberikan tugas rangkap kepada koordinator SP2TP dengan melakukan analisis jabatan pada semua petugas yang ada di puskesmas dan Dinas Kesehatan perlu mengadakan pelatihan untuk semua koordinator SP2TP Puskesmas dengan tujuan meningkatkan kompetensi petugas sehingga petugas mempunyai keahlian dalam pengelolaan data menjadi informasi yang lebih baik lagi.

\section{d. Sarana dan Prasarana}

Berdasarkan Peraturan Pemerintah Nomor 46 Tahun 2014 sarana dan prasarana yang seharusnya ada untuk mendukung SP2TP adalah komputer, formulir laporan, jaringan internet, dan alat transportasi dalam penyampaian laporan SP2TP. ${ }^{2}$ Jika sarana pendukung pelaksanaan SP2TP sudah tersedia di Puskesmas tetapi belum dimanfaat secara optimal, komputer hanya dimanfaatkan untuk mengetik surat-surat, dan komputer yang tersedia juga cuma satu diruang bendahara dan dimanfaatkan bergantian untuk pelaksanaan SP2TP, dan ini menjadi salah satu kendala pelaksanaan SP2TP di Puskesmas.

\section{Komponen Proses}

a Perencanaan Pelaksanaan sistem pelaporan SP2TP dari Puskesmas ke Dinas Kesehatan

Perencanaan pelaksanaan SP2TP seharusnya dilakukan di Dinas Kesehatan dan puskesmas. Perencanaan di tingkat Dinas Kesehatan dimulai dengan pengorganisasian pelaksanaan SP2TP, dengan merencanakan siapa yang akan menjadi penanggung jawab SP2TP dan koordinator SP2TP tingkat Dinas Kesehatan, kemudian dalam tahap perencanaan dinas kesehatan sebaiknya juga membuatkan jadwal dilakukan evaluasi dan pembinaan ke puskesmas-puskesmas, serta perlu dilakukan pula perencanaan terkait dengan pelatihan untuk pemegang program SP2TP puskesmas untuk meningkatkan kemampuan dan pengetahuan petugas terkait pelaksanaan SP2TP.
Perencanaan di tingkat puskesmas dilakukan dengan harapan bisa meningkatkan kemampuan manajemen puskesmas dalam merencanakan kegiatankegiatan yang akan dilakukannya yang meliputi seluruh kegiatan pokok di Puskesmas. Penyusunan rencana tingkat puskesmas dilakukan dalam 4 tahap yaitu tahap persiapan, tahap analisis situasi, tahap penyusunan Rencana Usulan Kegiatan (RUK) dan tahap penyusunan rencana pelaksanaan kegiatan (RPK), Pelaksanaan SP2TP di Puskesmas masuk kedalam bagian perencanaan di Puskesmas.

\section{b Pengorganisasian}

Berdasarkan Keputusan Menteri Kesehatan Nomor 44 Tahun 2016 bahwa untuk dapat terlaksana rencana kegiatan puskesmas, perlu dilakukan pengorganisasian. Ada dua macam pengorganisasian yang harus dilakukan, pertama pengorganisasian berupa penentuan para penanggung jawab dan para pelaksana untuk setiap kegiatan serta untuk setiap satuan wilayah kerja dengan mempertimbangkan kemampuan yang dimiliknya. Penentuan para penanggung jawab ini dilakukan melalui pertemuan penggalangan tim saat awal tahun kegiatan, kedua penggorganisasian berupa penggalangan kerjasama tim secara lintas sektoral. Hal ini pada tingkat puskesmas sudah dilaksanakan untuk Kota Padang, sedangkan untuk Dinas Kesehatan hal ini belum terlaksana. ${ }^{11}$

\section{c Pencatatan dan Pelaporan}

Pada tahap pencatatan kegiatan yang seharusnya dilakukan di Puskesmas adalah mencatat kegiatan didalam gedung puskesmas menggunakan RKK termasuk kartu status, KTP, register kunjungan, kartu KB dan register nomor indeks, mencatat kegiatan diluar gedung puskesmas, serta merekap/mencatat data kegiatan didalam dan diluar gedung puskesmas. Muninjaya (2004) yang dikutip oleh Pontoh (2013) berpendapat bahwa untuk pengembangan efektifitas sistem informasi manajemen puskesmas, standar mutu (input, proses, dan output) perlu dikaji dan dirumuskan kembali, masing-masing komponen terutama proses pencatatan dan pelaporannya perlu di tingkatkan. ${ }^{12}$

Kegiatan setelah pencatatan di puskesmas adalah pelaporan terpadu menggunakan tahun kalender yaitu 
bulan Januari sampai dengan Desember dalam tahun yang sama. Kegiatan menerima dan merekapitulasi data yang dicatat didalam dan luar gedung puskesmas kemudian dicatat hasil rekapitulasi tersebut kedalam formulir SP2TP serta membuat laporan SP2TP merupakan tugas pelaksana kegiatan SP2TP. Kegiatan mengumpulkan laporan SP2TP dan membuat laporan SP2TP dari masing-masing pelaksana kegiatan kemudian melaporkan hasil tersebut ke penanggung jawab SP2TP merupakan tugas koordinator SP2TP, sedangkan kegiatan melaporkan laporan bulanan dan tahunan dilakukan koordinator SP2TP bersama pelaksana kegiatan, arsip laporan SP2TP kemudian disimpan koordinator SP2TP. Kegiatan merekap data dilakukan oleh penanggung jawab program sebagai pelaksana kegiatan dansudah sesuai dengan pedoman SP2TP. ${ }^{11}$

\section{d Pengawasan dan Pengendalian}

Pengawasan merupakan suatu upaya melakukan penilaian sekaligus koreksi terhadap setiap penampilan pegawai untuk mencapai tujuan yang telah ditetapkan dalam rencana atau suatu proses untuk mengukur penampilan suatu program yang kemudian dilanjutkan dengan mengarahkannya sehingga tujuan yang telah ditetapkan tercapai. Pengawasan dengan menggunakan pengukuran kinerja aktual petugas yaitu dimulai dari pengamatan secara pribadi yang dilakukan pimpinan untuk memantau aktifitas pegawai di wilayah kerja puskesmas.

Pada Dinas Kesehatan semestinya pengawasan langsung dilakukan oleh Kepala Dinas Kesehatan terhadap kegiatan pelaksanaan SP2TP di wilayah kerja Dinas Kesehatan Kota Padang, kemudian perpanjangan tangan dalam mengawasi pelaksanaan SP2TP di Puskesmas, maka Kepala Dinas Kesehatan menunjuk satu orang koordinator SP2TP. Pengawasan dilakukan minimal setiap tiga bulan sekali. Pengawasan di Puskesmas langsung harus dilakukan oleh Kepala Puskesmas, yang dilakukan dengan cara melakukan montoring tiap bulannya dan melakukan evaluasi juga minimal 3 bulan sekali.

Pimpinan harus mulai melakukan pengawasan dengan cara melakukan monitoring rutin setiap bulan terhadap pencatatan dan pelaporan baik di tingkat Dinas Kesehatan maupun di tingkat Puskesmas, kemudian rutin melakukan evaluasi SP2TP sekali tiga bulan untuk melihat kendala dan permasalahan apa saja yang ada dalam pelaksanaan SP2TP di Puskesmas, setelah ditemukan kendala selanjutnya dicari upaya untuk mengatasi permasalahan permasalahan yang ada sebagai bentuk pengendalian dan tindak lanjut dari evaluasi yang telah dilakukan..

\section{Komponen Output}

Ada 11 Puskesmas menyampaikan laporan, tetapi yang diteliti ada empat Puskesmas yang memberikan laporan tidak tepat waktu yaitu Puskesmas $\mathrm{N}$, Puskesmas AA, Puskesmas SP dan Puskesmas B. Menurut peneliti permasalahan tersebut tidak terlepas dari koordinasi antar petugas pelaksana kegiatan di dalam gedung maupun di luar gedung puskesmas dengan koordinator SP2TP serta penanggung jawab puskesmas itu sendiri, tidak tersedianya sarana dan prasarana yang menjadi penunjang seperti komputer, dan jaringan wifi yang memadai, tidak adanya petugas khusus yang melakukan analisis dan penginputan data hal inilah yang menyebabkan laporan tidak tepat waktu disampaikan ke Dinas Kesehatan Kota dan sangat berpengaruh pada kualitas laporan SP2TP, semua permasalahan diatas menjadi bagian dari faktor yang menghambat pelaksanaan SP2TP Di Wilayah Kerja Dinas Kesehatan Kota Padang.

\section{SIMPULAN}

Pelaksanaan Sistem Pencatatan dan Pelaporan Terpadu Puskesmas (SP2TP) di Kota Padang Tahun 2018 belum berjalan secara optimal. Hal ini disebabkan beberapa permasalahan seperti SDM yang kurang memadai, Sarana dan Prasarana yang kurang, serta pengorganisasian sistem pelaporan yang tidak ada. Kesadaran Dinas Kesehatan terhadap pentingnya SP2TP ini juga masih sangat rendah.

\section{SARAN}

Pengiriman laporn SP2TP dapat berjalan baik, sebaiknya pihak Dinas Kesehatan Kota perlu meningkatkan kemampuan SDM terkait Pelaporan SP2TP, kelengakan sarana pendudukung, kejelasan struktur organisasi, sampai memperbaiki sistem pelaporan. Sistem pelaporan ini sebaiknya memanfaatkan media pengiriman laporan secara 
elektronik (email) atau membuat aplikasi pengiriman khusus serta diadakan fasilitas internet sehingga dapat mengurangi beban waktu yang dikeluarkan pada proses pelaporan laporan bulanan dan hal yang paling penting yaitu agar laporan tersebut tepat waktu diterima oleh pihak Dinas Kesehatan Kota.

\section{UCAPAN TERIMA KASIH}

Terima kasih kepada Kepala Dinas Kesehatan Kota Padang, Kepala Puskesmas se-Kota Padang dan seluruh pihak yang terlibat dalam memberikan motivasi, bimbingan dan kerjasama dalam penelitian ini

\section{DAFTAR PUSTAKA}

1. Kementrian Kesehatan RI (Kemenkes RI). Peraturan menteri kesehatan nomor 192 tahun 2012 tentang roadmap rencana aksi penguatan sistem informasi. Jakarta :Kemenkes RI; 2012.

2. Peraturan. Pemerintah Republik Indonesia Nomor 46 Tahun 2014 tentang Sistem Informasi Kesehatan. Jakarta; 2014.

3. Suryani ND, Solikhah. Sistem pencatatan dan pelaporan terpadu puskesmas (SP2TP) di wilayah Dinkes Dompu Provinsi NTB. Jurnal Kesmas. 2013; 7 (01):23-7.

4. Kemenkes RI. Peraturan menteri kesehatan nomor 75 tahun 2014 tentang pusat kesehatan masyarakat. Jakarta: Kemenkes RI; 2014.

5. Aprizanda. Pelaksanaan sistem informasi kesehatan on line dalam peningkatan objektifitas kerja di dinas kesehatan provinsi Sumatera Barat [tesis]. Medan: Fakultas Kesehatan Masyarakat Universitas Sumatera Utara; 2012.hlm.48-50.

6. Sugiyono. Metode penelitian kuantitatif kualitatif. Yogyakarta: Alfhabeta; 2014.hlm.35-6.

7. Kemenkes RI. Petunjuk teknis pelaksanaan sistem informasi kesehatan. Jakarta: Kemenkes RI; 2011.

8. Vidyanto. Evaluasi komunikasi data SP2TP antara puskesmas dan dinas kesehatan di kabupaten Tolitoli Provinsi Sulawesi Tengah. Jurnal Kesehatan Tadulako. 2018;4(1):41-9.

9. Wahab SA. Analisis kebijakan. Jakarta: Bumi Aksara; 2017.hlm.85-7.

10. Tahir. Evaluasi pelaksanaan program sistem pencatatan dan pelaporan terpadu puskesmas di puskesmas Abeli Kota Kendari [tesis]. Kendari: Universitas Halu Oleo Fakultas Kesehatan Masyarakat; 2015.hlm.37-8.

11. Kemenkes RI. Peraturan menteri kesehatan nomor 44 tahun 2016 tentang pedoman manajemen puskesmas. Jakarta: Kemenkes RI; 2016.

12. Pontoh I. Dasar-dasar ilmu kesehatan masyarakat. Jakarta: Inmedia; 2013.hlm.25-6. 